\title{
TESORILLO DE MONEDA CARTAGINESA HALLADO EN LA TORRE DE DOÑA BLANCA (Puerto de Santa María, Cádiz)
}

\author{
POR \\ CARMEN ALFARO ASINS Y CARMEN MARCOS ALONSO \\ Museo Arqueológico Nacional. Madrid
}

\section{RESUMEN}

Entre los materiales numismátices hallados en el importante yacimiento de la Torre de Doña Blanca (Puerto de Santa Maria, (ádiz), destaca un tesorillo de 56 monedas cartaginesas de cobre aleado con mucho plomo, que proporciona la cronologia final de la vida del yacimiento durante la Segunda Guerra Púnica. Son monedas ade necesidad» que con probabilidad fueron acunadas en Cartago y distribuidas en los momentos de penuria monetaria entre las tropas cartaginesas de los distintos frentes bélicos.

\section{SUMMARY}

Among the numismatic finds from the important Torre de Doña Blanca site (Puerto de Santa Maria. (ádiz). a small hoard of 56 Punic coins calls for special comment. They appear to date the end of the settlement to sometime during the Second Punic War. The coins, which are of a copper alloy with a high, lead content, constitute an "emergency" issue. It is probable that they were struck at Carthage during a period of monetary crisis and were subsequently paid to Carthaginian forces engaged in the conflict with Rome.

La actividad arqueológica en la zona de la Torre o Castillo de Doña Blanca (Puerto de Santa Maria, Cádiz), se ha venido desarrollando de forma casi ininterrumpida a lo largo de diversas campañas desde el año 1979. Las excavaciones realizadas bajo la dirección del Dr.D. Diego Ruiz Mata han dado como resultado el conocimiento de cuatro yacimientos con una cronología que abarcaria desde la Edad del Cobre hasta finales del siglo III a.C.

El conjunto arqueológico, que está formado por un poblado calcolítico (La Dehesa), un asentamiento de época púnica (Las Cumbres) y el propio yacimiento protohistórico de Doña Blanca junto con su necrópolis, se ubica entre la ladera meridional de la Sierra de San Cristóbal y la margen izquierda del río Guadalete, en el término municipal de El Puerto de Santa Maria.

En concreto, de las excavaciones sistemáticas realizadas en el asentamiento de la Torre de Doǹa Blanca, identificado por numerosos investigadores con el Puerto de Menesteo, se desprende la existencia de un hábitat continuado desde la primera mitad del siglo viI hasta finales del siglo II a.C. El estudio de los materiales que corresponden a los niveles iniciales, ha llevado al Dr. Ruiz. Mata, a considerar el yacimiento como una fundación fenicia realizada por colonos procedentes, probablemente, de la ciudad de Tiro. Así lo ponen en evidencia tanto el sistema urbanistico de viviendas aterrazadas y el tipo de técnicas constructivas empleadas para su realización, como los restos cerámicos que, por ejemplo, muestran el repertorio completo de la vajilla de engobe rojo fenicio (platos, oinocóes, quemaperfumes, lucernas....).

En estrecha relación con la Torre de Doña Blanca está el poblado indígena de Las Cumbres, en donde se advierte, para estos momentos del siglo viII a.C., un proceso de rápida asimilación a los nuevos modos orientales. Este yacimiento, que parece que se abandona al poco tiempo de la fundación de la ciudad, se encuentra situado sobre el punto más elevado de la Sierra de San Cristóbal, y su evidente valor estratégico, debió propiciar de nuevo el establecimiento de una población entre los siglos IV y III a.C., por lo que constituye otro de los núcleos de interés para el estudio de la circulación monetaria de la zona.

En la zona de la Torre de Doña Blanca, en etapas posteriores $\mathrm{y}$, como resultado de establecimientos 


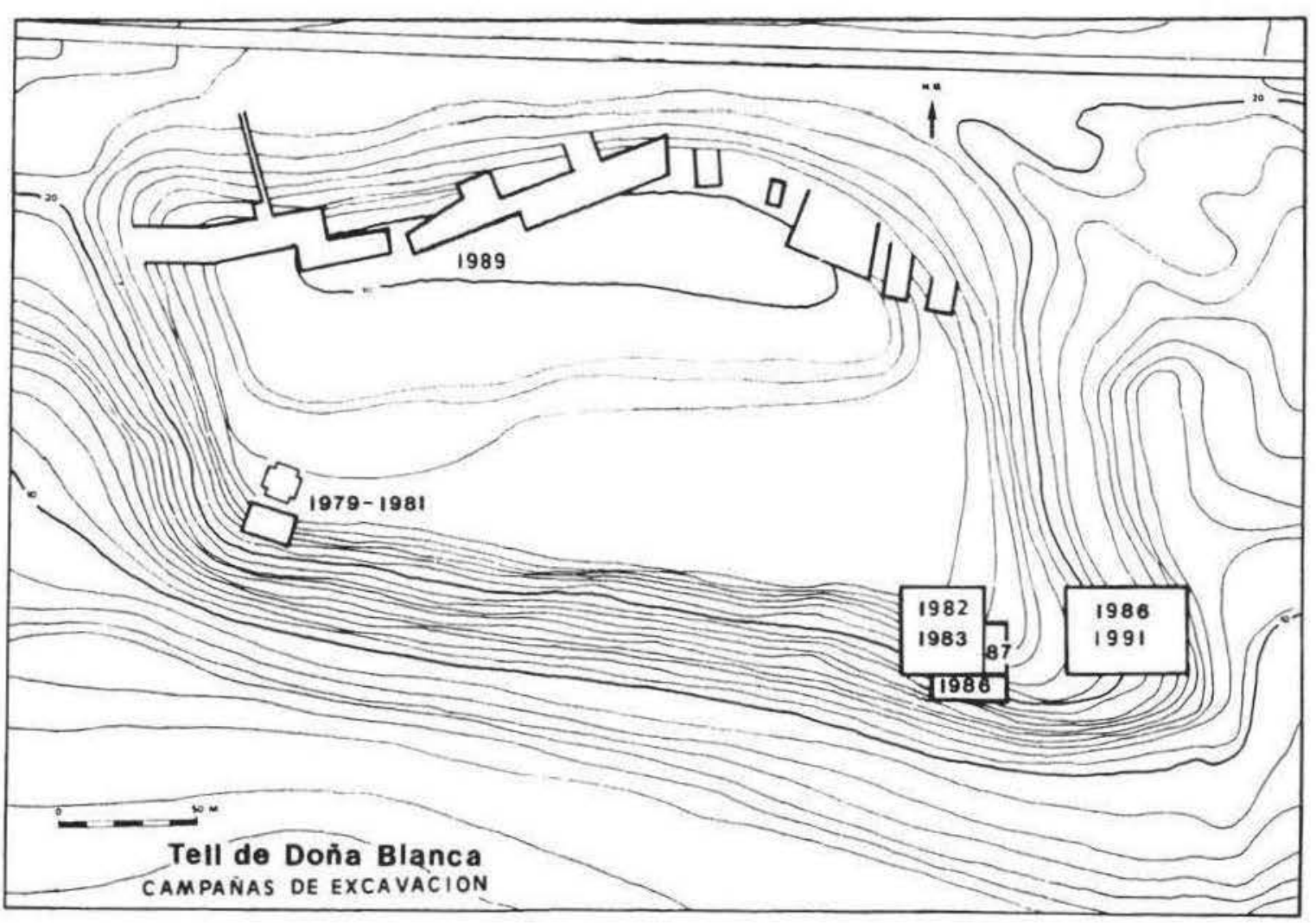

Figura 1.---Plano del yacimiento con las distintas campanas de excavación realizadas.

ya marginales, únicamente se han podido constatar algunos restos aislados de época romana, vestigios de una pequeña población almohade entre los siglos xil y xiII y la torre vigia del siglo xV que da nombre al yacimiento. La superposición de estos niveles de habitación ha dado como resultado la formación de un tell de unos $300 \mathrm{~m}$ en su eje E-O y $200 \mathrm{~m}$ el eje $\mathrm{N}-\mathrm{S}$ junto a una potencia estratigráfica que, en algunos sectores, Ilega a alcanzar los 8-10 $\mathrm{m}$ de altura. Con una ubicación sobre una plataforma muy próxima al mar, su desarrollo entre los siglos viII-III a.C., siempre estuvo favorecido por su posición como puerto y por su evidente relación a lo largo de este periodo con la ciudad de Gadir ${ }^{\text {. }}$

\footnotetext{
1 Como bibliografia fundamental remitimos a Ruiz Mata, D.: Las cerámicas fenicias del Castillo de Doña Blanca, (El Puerto de Santa Maria). Aula Orientalis, 3, 1985, pp. 241-263; id.: La formación de la cultura turdetana en la Bahia de Cádiz a través del Castillo de Doña Blanca. Actas de las I Jornadas sobre el Mundo Ibérico (Jaẻn, 1985), Jaèn, 1987, pp. 299-314; id.: Ruiz Mata, D., Pérez, C.: El Túmulo I de la necrópolis de Las Cumbres (Puerto de Santa Maria, Cádiz) Turtesos. Arqueología protohistórica del Bajo Guadalquivir. Sabadell (Barcelono), 1989. pp. 591 y ss.; Ruiz Mata, D.: Los fenicios de época arcaica (siglos vill-vi a.C) en la Bahía de Cádiz: estado de la cuestión. Studos Orientais, 4, Lisboa, 1993, pp. 23-72.
}

\section{EL MATERIAL NUMISMÁTICO 2}

El número de monedas halladas en el yacimiento del Castillo de Doña Blanca entre 1979 y 1989. tanto esporádicamente como en excavación, es escaso - no llega al centenar- aunque de gran interés, y cronológicamente pertenecen a tres periodos históricos:

- El primero corresponde al siglo III a.C., con 70 ejemplares $(87,50 \%$ del total) de Gadir y Cartago de distintas cecas y cronologías, que son el testimonio de la circulación monetaria del yacimiento protohistórico en el último siglo de su vida. Algunas de estas monedas han sido halladas en contexto arqueológico, por lo que su estudio tiene un doble

\footnotetext{
2 Una visión más detallada en Alfaro Asins, C. y Marcos Alonso, C.: Avance sobre la circulación monetaria en la Torre de Doña Blanca (Puerto de Santa Maria, Cádiz), II Congreso Internacional El Estrecho de Gibraltar, (Ceuta, 1990) (en prensa) (En adelante citado como Alfaro y Marcos, TDB). Desde estas páginas nuestro agradecimiento al Dr. Ruiz Mata por habernos confiado el estudio del material numismático hallado en el yacimiento. Igualmente nuestra gratitud para el Dr. Giles, Director del Museo de El Puerto de Santa Maria y todo el personal del mismo por las facilidades recibidas para la consulta de los fondos numismáticos que conservan.
} 
interes. Esta circulación monetaria del yacimiento ademas proporciona la evidencia del comienzo de la acunación en la peninsula iberica que. salvo en las colonias griegas de Emporion y Rhode, se inicia en el sur en la ciudad de Gadir

El segundo bloque cronológico lo situamos entre el siglo 11 a.C. y el reinado de Anastasio (491 d.C.). De esta larga ctapa solo contamos con 4 monedas $(5 \%$ del total) que evidentemente se han hallado fuera de contex to arqueológico y son pérdidas fortuitas posteriores a la vida del yacimiento. Dos de estas monedas corresponden a las cecas de Gadir del siglo $11-1$ a.C. ${ }^{+}$y Seks del I a.C. ' y las otras dos son ases romanos imperiales, uno de Nerón "y otro de Adriano?

- El tercer periodo corresponde a la Edad Mcdia con 6 monedas halladas $(7,5 \%$ del total $)$. Dos son hispano-árabes, la primera un felis de primera época ${ }^{8}$ y la segunda un dirhem de la Taifa Abbadi de Sevilla fechado entre los años 4.38-448 de la Hégira/1047-1056 d.C. 9 . Otras tres son cristianas del reino de Castilla-León, dos respectivamente obolo $y$ dinero (c. 1252) de Alfonso $X^{11}$ y la tercera una blanca (c. 1406-1454) de Juan II "I. La última moneda es cristiana pero incierta a causa de su mala conservación. Estas monedas, halladas en superficie. probablemente están en relación con el poblado almohade que se asentó sobre el yacimiento protohistórico, con la reconquista de la zona en 1261 por Alfonso $\mathrm{X}$ y con la torre o castillo del siglo $\mathrm{xv}$ supuestamente relacionado con la reclusión de doña Blanca, mujer de Pedro I. Por último, también casualmente, se han hallado 8 maravedis resellados de 1618 y un céntimo de 1870 .

\footnotetext{
En este sentido. conviene citar también los hallazgos monetarios realizados en el cercano poblado de las Cumbres en la Sierra de San Cristobal, donde se han hallado monedas de Massalia. Cartago de distintas cronologias y Ebusus.

Alfaro Asins. C.: Las monedas de Gadir Gades. Madrid, 1989 Seric VI.I.. sin mas precisiones por el mal eslado de conservación de la moneda

Alfaro Asins, C.: Observaciones sobre las monedas de Seks segun la colección del M.A.N. Almuñecar Arqueologia e His. toria III. Granada. 1986. Grupo IV.B., sin poder precisar si pre. senta la letra aleph tendida o vertical por tratarse de un fragmento de moneda.

A Sutherland, C. H. V. The Roman Imperial Coinage, I. Londres, 1984, p. $168, n^{\circ} 300$

Mattingly, H. y Sydenham. E. A.: The Roman Imperial Co. inage. II, Londres, 1926, p. 427, $\mathrm{n}^{\circ} 67 \mathrm{x}$.

Walker, J: A Catalogue of the Arah-Byzantine and post Reform Limaiyad Coins. Londres, 1956. n" 649-659

"Vives y Escudero, A.: Monedas de las dinastias arähigo. españolas, Madrid. 1893, n" 891.906.

10 Collantes, E.: Notas sobre las monedas de Alfonso X. Acta Numismática, V1, 1976 , p. $155, n^{\circ} 6$.

"Heiss, A. Descripcion General de las Monedas HispanoCristianas, I, Madrid, 1865, Lám. 12, $\mathrm{n}^{\circ} 19.21$
}

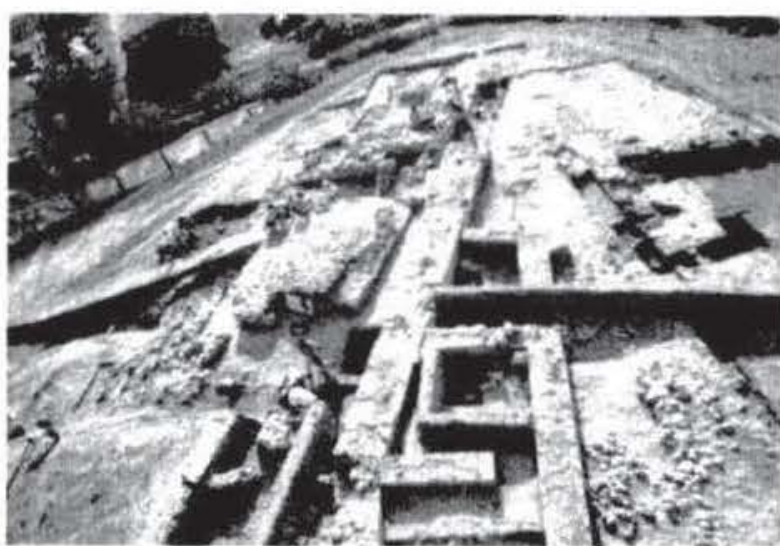

trgura 2. Jista de la rona donde se hallo el terorillo

\section{EL TESORILLODE MONEDA CARTAGINESA}

Este tesorillo, que podemos encuadrar dentro de los del tipo conocido como "pérdidas accidentales", es $\sin$ lugar a dudas el material numismático más interesante del poblado. Está formado por 56 monedas cartaginesas de acobre", posiblemente siclos shekels, que se acuñaron, con toda probabilidad, en la propia Cartago durante la Segunda Guerra Púnica $^{17}$. Las monedas que lo forman fueron halladas durante la campaña de 1986 en el sector SE/SO del yacimiento. La zona, denominada "espigon», se encuentra próxima al puerto del poblado y corresponde a las estructuras defensivas de éste. En el área se han excavado los restos de una doble muralla del tipo conocido como de "caja» o de "casamatas», construida a base de sillares que presentan un almohadillado helenistico. El hallazgo tuvo lugar en una de las habitaciones-almacén que determinan esta muralla, en conereto, hacia la esquina NE del «Almacén I m, junto a uno de los muros del habitáculo.

El contexto arqueológico en el que apareció el tesorillo ofrece materiales de gran interés entre los que se encuentra un ánfora greco-itálica y otra cartaginesa, ambas completas, junto a otros restos de ánforas, un fragmento de cerámica de Kouass, asi

2 Una noticia sobre estas monedas en Alfaro Asins, $C_{\text {, y Marcos }}$ Alonso, C: Nota sobre el tesorillo de moneda cartaginesa de la Torre de Doña Blanca (Puerto de Santa Maria, Cádiz). X/th /nternational Numismatic Congress, (Bruselas, 1991) (en prensa).

Jenkins, G, K. Some Coins of Hannibal's time. Studi per Laura Breglia. Parte I. Supplemento al Bollettino di Numismalica, 4, 1987, p. 224, insiste en que estas monedas, numerario base del conflicto, se acunaron en Cartago junto a otras pequeñas piezas de plata y electro del mismo estilo, todas con ejes verticales como es caracteristico en la metrópolis. (En adelante citado como Jenkins. 1987). 


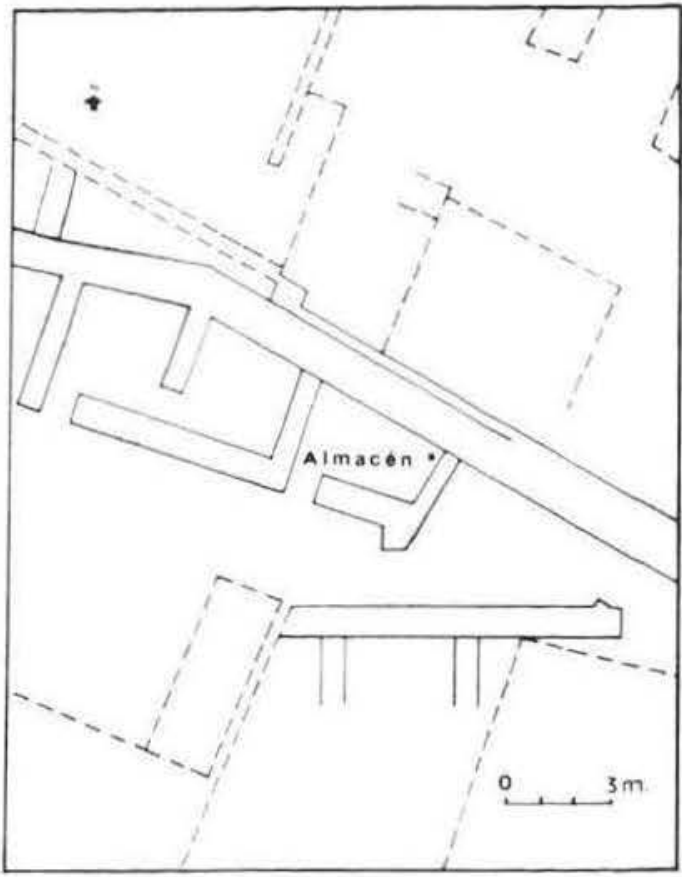

fasara ; Plano de la voma donde se ballo el resorillo

como cazuclas, platos y cuencos con carena y reslos de huesos de animales, lo que hace pensar en que la función de este espacio fuera el de almacenaje. En la puerta de la misma habitación se halló tambiẻn una moneda hispano-cartaginesa acuñada, según L. Villaronga, con posterioridad al año 221 a.C. en una zona alejada del yacimiento ${ }^{14}$, que presenta un alto grado de desgaste por la intensa circulación a que fue sometida.

Las monedas aparecieron pegadas unas a otras con aspecto de cilindro metálico y con manchas de materia orgánica a su alrededor, por lo que originariamente debicron estar metidas en una especie de saquito de tela o cuero, de forma tubular, preparado ex profeso para contener y llevar monedas de ese diámetro. Hay constancia del uso de cajas, bolsas y saquitos con monedas cartaginesas en tumbas púnicas $^{15}$, aunque no conocemos su hallazgo en otro tipo

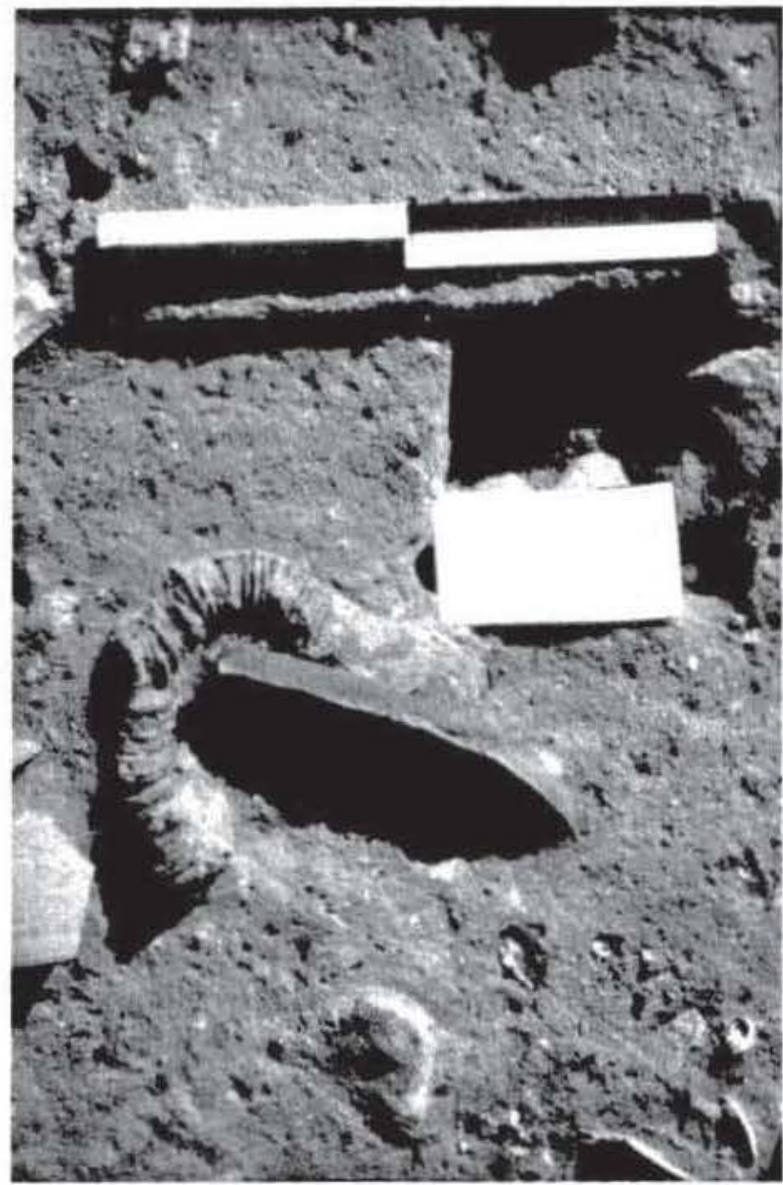

Figura 4. Las monedas en el momento de su halla/go.

de contexto arqueológico ${ }^{16}$. Este saquito con monedas es el testimonio de la precipitada huida de su poseedor, probablemente un soldado, ante los graves acontecimientos que acabaron con la vida del yacimiento.

La tipologia de las 56 monedas. salvo distintas variantes artisticas y estilisticas, es muy similar y muestra en anverso la cabeza de Tanit a izquierda, con espigas en el pelo, que presenta ligeras varian- it Villaronga, L.: Las monedas hispano-carlaginesas, Barce. lona, 1973. Clase IX.2. (En adelante citado como Villaronga. $1973)$.

is Visona, P.: The Yale Hoard of Punic Bronze coins from Malta, Rivista di Studi Fenici, XVIII, 2, 1990, p. 171. recoge varios ejemplos de monedas halladas en cajas, bolsas y saquitos en tumbas punicas de Cartago, Leptis Magna, Lilibeo, Olbia y Monte Luna. También en idéntica disposición fueron encontrados cerea de cien dineros de vellón de Fernando IV en una inhumación medieval, probablemente de un soldado, en la aldea de San Pedro de Merida. Cfr. Almagro Basch. M. y Marcos Pous. A.: Excavaciones de ruinas de época visigoda en la aldea de San Pedro de Mérida. Revista de estudios extremeños, 1958, p. 11. donde aparecen citados como de Fernando III. Las circunstancias concretas del hallazgo de las monedas y otros detalles que no figuran en la publicación nos han sido facilitados por nuestro companero y amigo Alejandro Marcos Pous.

in En una disposición similar, según nos comunica amablemente Manuel Abad Varela, se halló un tesorillo de denarios en Lancia. También conocemos restos de una bolsita con 13 vellones atribuidos a Alfonso I cel Batalladorm hallados en Alarcos que debieron pertenecer a algún soldado que, como el de la Torre de Doña Blanca, murio en la famosa batalla de 1195 . C fr. Canto, A.: Hallazgos numismáticos en Alarcos, 1 Congreso de Arqueologia Medieval, t. V, Huesca, 1985, pp. 209-213. 
tes en el grabado de los distintos cuños, y en reverso un caballo a derecha sobre linea de exergo, generalmente con ron/al ${ }^{1}$, representando en distintas disposiciones y acompañado por diferentes simbolos y ocasionalmente letras púnicas diferenciadoras de emisiones (i). Estas series se emitieron en grandes cantidades como se aprecia por la variedad de cuños utilizados, aunque la mala conservación general de este tipo de monedas hace dificil poder precisar más en este sentido.

Las diferencias en los reversos nos hacen agrupar las monedas, por órden de emison, en seis tipos fundamentales. El grupo más antiguo con 3 monedas ${ }^{1 \times}$, presenta el caballo al paso con la cabeza vuelta. Un ejemplar lleva la letra 'aleph y otro una gimel. La cabeza de Tanit aparece representada con el pelo corto y redondeado, con pendiente de triple colgante que sólo se aprecia en el ejemplar n" 2, y cuello triangular con la base más ancha que parece estar rematada por collar con apéndices verticales. Los cuños de anverso y reverso son distintos en las tres piezas.

El segundo tipo, el más abundante con 24 monedas, presenta el caballo parado con la cabeza vuelta ${ }^{19}$. Tres ejemplares llevan la letra 'aleph, dos una het, uno probablemente la letra mem, otro una sade y cinco las letras aleph y sade conjuntamente. Las monedas de este grupo poseen una acuñación menos cuidada y los pesos más irregulares del conjunto. Aunque el mal estado general de las monedas no permite realizar el detallado estudio de los cuños, en principio, nos parece observar que tanto los de anverso como los de reverso son diferentes, a excepción de los ejemplares nn. 24 y 25 , con letra het, cuyos reversos proceden del mismo cuño. En general la cabeza de Tanit presenta pelo corto y de formas redondeadas como en el grupo anterior, con pendiente mayoritariamente de un colgante ( $\mathrm{nn}$. 11$13,20,25)$ aunque en un ejemplar se ve con claridad que es triple ( $\left.n^{\circ} 24\right)$. El cuello también es triangular con la base más ancha y a veces rematado por collar plano o con apéndices verticales. La cabeza de Tanit de estas monedas se aparta estilísticamente bastante de las que encontramos en los grupos siguientes. Algunas parecen estar reacuñadas pero

\footnotetext{
17 Para Baldus, H. R.: Die Münzprägung der numidischen Königreiche, Die Numider, Bonn, 1979, pp. 187-191, el ronzal en estas monedas está en relación con la presencia de mercenarios númidas en el ejército cartaginés.

is Jenkins, G. K.: Sylloge Nummorum Graecorum. The Royal Collection of Coins and Medals Danish National Museum. North Africa Syrtica-Mauretania, Copenhagen, 1969, n 302-306. (En adelante citado como SNGCop).

${ }^{19}$ SNGCop 307-314.
}

en ninguna se aprecian restos de la tipologia de la moneda original, aunque sabemos que ejemplares de este tipo se reacuñaron sobre piezas de Hieron II de Siracusa.

El tercer grupo con una moneda, presenta el caballo parado con la cabeza vuelta y detrás estre$11 a^{2}$. Esta moneda lleva la letra het entre las patas del caballo. Aunque el tipo de reverso es similar. salvo por el símbolo, al grupo anterior, el estilo de la cabeza de Tanit es idéntico al que encontramos mayoritariamente en el grupo siguiente. La estrella del reverso en otros ejemplares conocidos también puede tener 6,8 o 9 rayos. Como en el grupo anterior, también se conocen ejemplares reacunados sobre monedas de Hierón II.

El tipo cuarto, con 16 monedas, presenta el caballo parado con ronzal, la cabeza vuelta y detras palmeta ${ }^{21}$. Cuatro ejemplares llevan la letra gimel y una la letra nun o lamed. Estas monedas presentan un estilo muy homogéneo, con una cabeza de Tanit casi exacta en todos los ejemplares aunque pequenas diferencias parecen descartar su procedencia de un mismo cuño, a excepción de las piezas nn. 32 y 33. El peinado, con el pelo recogido en la nuca que da la apariencia de una especie de moño bajo, el pendiente de un colgante y cuello estrello y recto, a veces rematado por collar plano, es similar al de algunas monedas contemporáneas, fundamentalmente de plata ${ }^{22}$. Como excepción la moneda $n^{\circ} 43$ se aparta estilisticamente algo del modelo descrito y se asemeja más a las monedas de Grupo II.

El quinto grupo, con 11 monedas, presenta el caballo al paso y detrás caduceo ${ }^{23}$. Tres ejemplares llevan la letra ayin. La cabeza de Tanit presenta dos estilos diferentes. Uno es bastante parecido al de las monedas del grupo anterior (nn. 46, 53, 54 y $55)$ y a su vez casi idéntico al que presentan algunas monedas de electro del grupo XV de Jenkins y Lewis $^{24}$. El otro estilo de cabeza de Tanit presenta pelo corto más floreado con rizos flotantes en la nuca, como otros ejemplares de electro del mismo grupo anterior y como algunas de las monedas posteriores tipo «tesoro de El Djem» ${ }^{25}$. Nos parece encontrar

\footnotetext{
20 SNGCop 315-316.

2 SNGCop 317-319.

22 Jenkins, 1987, 1/4 de shekel Q1-Q22.

23 SNGCop 326-329.

${ }^{24}$ Los ejemplares más parecidos son los dados a conocer por Alfaro Asins, C.: Lote de monedas cartaginesas procedentes del dragado del puerto de Melilla, Numisma, 232, 1993, pp.

2s Jenkins, G. K. y Lewis, R. B.: Carthaginian Gold and ElecIrum Coins, Londres, 1963, Grupo XV, $\mathrm{n}^{\circ} 476$. (En adelante citado como Jenkins y Lewis). 9-46, nn. 13-15. (En adelante citado como Alfaro, Melilla).
} 
identidad de cuños de anverso entre las monedas $45-48,47-51,54-55$ y quizas 46-53. aunque estas últimas con muchas dudas por la mala conservación de la parte delantera de la cabeza de Tanit en la moneda $n^{\circ} 46$.

El sex to y último tipo lo forma una moneda, probablemente la más moderna y rara del conjunto, que presenta el caballo parado con ronzal, detrás una estrella de ocho rayos y delante la letra 'alin. Además de los ejemplares que conocemos hallados en Melilla y Ampurias, sabemos de la existencia, gracias a la información de Paolo Visonà, de otras dos piezas en el Museo Británico, otra en el Museo del Bardo y una más sin ayin formando parte del tesoro de Bujia.

En este tesoro falta un tipo de moneda atribuida por G.K. Jenkins también a la Segunda Guerra Púnica y presente en otros tesoros como el de Bujia, que se caracteriza por mostrar en reverso el caballo parado con la cabeza vuelta y detrás caduceo ${ }^{20}$.

La metrologia de estas monedas, con un peso medio general de 7,15 grs., las acerca al peso teórico del siclo/shekel por lo que G.K. Jenkins las asigna ese valor ${ }^{27}$. Las monedas del primer y segundo grupo muestran los pesos más bajos del conjunto con medias de 6,03 y 5,88 grs. respectivamente, por el mayor desgaste sufrido, al ser las piezas más antiguas, propiciado por su alto contenido en plomo. Los grupos tercero, cuarto y quinto ofrecen pesos medios cercanos a los del patrón metrológico teórico del siclo/shekel con medias de $7,17,7,13$ y 7,26 grs. Por último la moneda que forma el grupo sexto presenta 9,44 grs., un alto peso que probablemente se debe a la buena conservación del ejemplar por ser la pieza más reciente del tesoro.

Los análisis metalográficos realizados a estas monedas evidencian, en general, un alto porcentaje de plomo en su composición, que en algunos casos llega a cerca del $90 \%{ }^{28}$, salvo en algunos ejempla-

\footnotetext{
26 SNGCop 320-321.

27 Jenkins, 1987, p. 217.

${ }_{2 \times}$ Los porcentajes menor y mayor de las monedas de cada uno de los 6 grupos es: Grupo $1^{\circ}$ : Fe: $0,06-0,20 \%$; $\mathrm{Ni}: 0,02$ $0,06 \%$; Cu: $57,03-92,85 \%$; $\mathrm{Zn}$ : -; As: $0,29-0,50 \%$; Ag: 0,01 $0,16 \%$; $\mathrm{Sn}: 2.06-3.47 \%$, Sb: $0,05-0,13 \%$ y $\mathrm{Pb}: 3,52-40,24 \%$. Grupo $2^{\circ}$ : Fe: $0,06-0,39 \%$; Ni: $\quad 0,13 \%$; Cu: $14,61-63,67 \% ; \mathrm{Zn}$ : -; As: $-1,57 \%$; Ag: - 0,09\%; Sn: 0,09-3,20\%, Sb: 0,01-0,49\% y $\mathrm{Pb}: 33,94-84,75 \%$.. Grupo $3^{\circ}$ : $\mathrm{Fe}: 0,15 \%$; $\mathrm{Ni}: 0,09 \%$; $\mathrm{Cu}$ $25,17 \%$; $\mathrm{Zn:}-;$ As: -: Ag: $0,01 \%$; Sn: $0,30 \%, \mathrm{Sb}: 0,01 \%$ y $\mathrm{Pb}$ : $74,10 \%$.. Grupo $4^{\circ}$; Fè: $0,01-0,35 \%$; Ni: $0,03-0,16 \%$; Cu: 15,20 $60,90 \% ; \mathrm{Zn}:-;$ As: $-0,77 \% ; \mathrm{Ag}: 0,01-0,02 \%$; $\mathrm{Sn}: 0.06-2,45 \%$, Sb: $0,01-0,370 \%$ y $\mathrm{Pb}: 35,83-83,73 \%$.. Grupo $5^{\circ}$; $\mathrm{Fe}:-0,21 \%$; $\mathrm{Ni}:-0,34 \%$; Cu: $15,14-54,07 \% ; \mathrm{Zn}:-;$ As: $-0,33 \% ; \mathrm{Ag}$ : $0,01 \%$; Sn: $0,51-2,90 \%, \mathrm{Sb}: 0,01-0,34 \%$ y $\mathrm{Pb}: 42,48-83,90 \%$. y Grupo 6\%: Fe: $0,12 \%$; Ni: $0,07 \%$; Cu: $33,06 \% ; \mathrm{Zn}:-;$ As: $0,41 \%$; Ag: $0,16 \% ; \mathrm{Sn}: 1,43 \%$, $\mathrm{Sb} ; 0,02 \%$ y $\mathrm{Pb}: 64,83 \%$.
}

res del primer grupo que tienen aún un alto contenido en cobre situado en torno al 90-92\% frente al $3-5 \%$ de plomo y cerca del $3 \%$ de estaño, como componentes fundamentales. Esta gran cantidad de plomo en su composición las diferencia claramente de las acuñadas en Sicilia y en la península ibérica que presentan altos porcentajes de cobre, como hemos comentado, y es un dato más para circunscribir su emisión al área de Cartago ${ }^{24}$, donde sabemos que el plomo era muy abundante y se explotaba en las cercanias de la ciudad "".

Los hallazgos de este tipo de monedas son abundantes y se situan fundamentalmente en la zona litoral mediterránea. Conocemos algunos tesoros de composición similar al de este yacimiento. Uno se halló en 1929 en Bujía (Argelia), antigua Saldae, y estaba formado por más de 2500 monedas de bronce de las que E.S.G. Robinson pudo examinar unas 130 de tipología similar a las de nuestros grupos $1^{\circ}$, $2^{\circ}, 3^{\circ}$ y $4^{\circ}$, junto a otros tipos de monedas ausentes en la Torre de Doña Blanca como el SNGCop 320321,353 y 397 , estos dos últimos fechados por G.K. Jenkins en el 210-202 a.C., por lo que la ocultación del tesoro tendría lugar hacia el 200 a.C. ${ }^{31}$. Otro tesoro se halló en Túnez en 1965 y estaba formado por mas de 300 ejemplares de nuestros grupos $1^{\circ}$, $2^{\circ}, 3^{\circ}, 4^{\circ}$ y $5^{\circ} 3^{2}$. Otros dos tesoros proceden de la isla de Pantelleria, antigua Cossura; el primero, aparecido en 1895 , contiene 48 monedas de nuestros grupos $1^{\circ}$ al $5^{\circ}$ cuya ocultación, según Jenkins, se produjo hacia el 200 a.C. ${ }^{33}$; el segundo, hallado en fecha desconocida y más dudoso, está formado por 42 monedas de bronce de las que 33 son de Cartago, algunas de los tipos del tesoro de la Torre de Doña Blanca, y 9 de Cossura $^{34}$. Por último, una moneda de nuestro grupo $2^{\circ}$ se halló en 1965 junto a otras

\footnotetext{
24 Jenkins, 1987, p. 217. El principal punto en que se apoya este autor para atribuir este tipo de monedas a la ceca de Cartago son los hallazgos. Otro argumento es la posición de cuños vertical de estas monedas que caracteriza a la ceca de Cartago en contraposición con las cecas de Sicilia y Cerdeña.

${ }^{30}$ Ejemplo de la abundancia de plomo en la zona es la llamada Yabal Rusas o "montaña de plomo» que se localiza en las afueras de Tunez.

31 Jenkins y Lewis, p. 49. Thompson, M., Morkholm, O. y Kraay, C. M.: An Inventory of Greek Coin Hourds, New York, 1973, $n^{\circ}$ 2296. (En adelante citado como IGCH). Salama, P.: Huit siècles de circulation monétaire sur les sites cotiers de Mauretanie centrale et orientale (III ${ }^{e}$ siècle av. J.C.V ${ }^{\circ}$ siècle ap. J.C). I Symposium Numismático de Barcelona, II, Barcelona, 1979. $\mathrm{n}^{\circ}$ inv, 128

32 IGCH n ${ }^{\circ} 2295$

33 $\mathrm{IGCH} \mathrm{n}^{\circ} 2297$

34 IGCH n ${ }^{\circ} 2298$. Las monedas de Cartago corresponden a los tipos SNGCop 94, 109, 144-178, 302-329 y las de Cossura al SNGCop 449.
} 


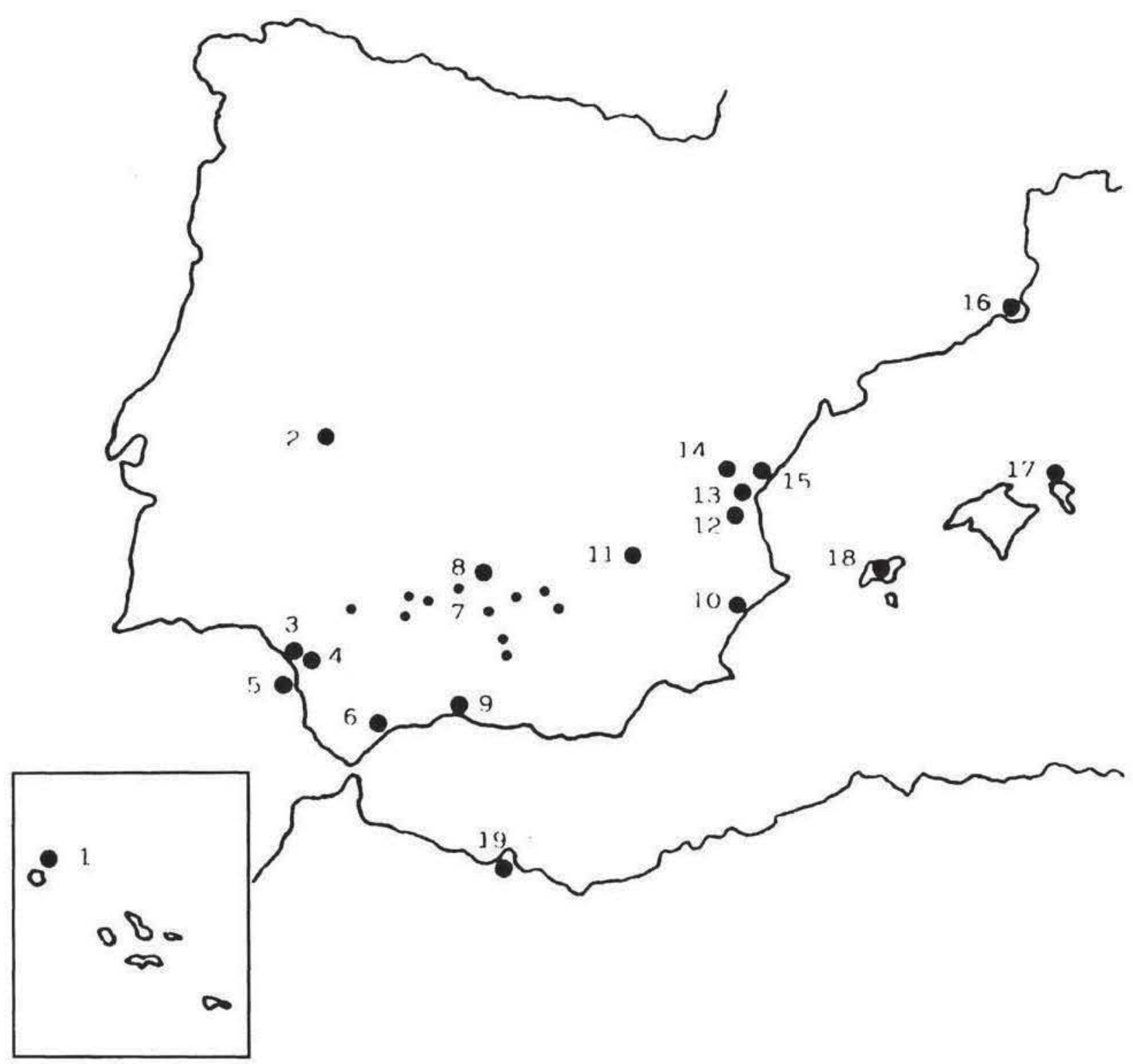

Figura 5.- Hallazgos de monedas similares a las del tesorillo en el extremo Mediterráneo occidental.

31 de ceca Sarda en Wadi Sofeggin (Libia), fechandose igualmente la ocultación del tesorillo a finales del siglo III a.C. ${ }^{35}$.

En cuanto a hallazgos individualizados sabemos que E.G. Robinson, según G.K. Jenkins, recogió gran cantidad de estas monedas en colecciones de Cartago y Túnez así como de Constantina, Cherchel, Argel, Trípoli y que algunas monedas procedian de las

\footnotetext{
${ }^{35} \mathrm{IGCH} \mathrm{n^{ \circ }} 2294$.
}

excavaciones de Sabrata y Cartago ${ }^{36}$. De las excavaciones más recientes dentro de la "Campaña internacional de salvamento de Cartago» se reseñan tres monedas de los grupos SNGCop 302-313, dos de ellas de las excavaciones de la Universidad de Michigan en 1976-1982 y una de la misión francesa durante $1974-1976^{37}$. A estas monedas hay que añadir

\footnotetext{
36 Jenkins, 1987, pp. 216-217

37 Visona, P.: Punic and Greek Bronze Coins from Carthage. American Journal of Archaeology, 89, 1985, pp. 671-672.
} 
otras 24 mas de la antigua colección Jackson halladas en el siglo pasado en las ruinas de la propia Cartago que en la actualidad se conservan en el Hunter Coin Cabinet de (ilasgow ${ }^{\text {ix }}$.

Por el contrario (i.K. Jenkins señala escasos halla/gos en Sicilia, solo 4 ejemplares en Morgantina que se ven aumentados a 6 según la reciente publicación de las excavaciones de las Universidades de Princeton, Illinois y Virginia entre 1955 y $1981^{\text {iv }}$. A estos hallazgos hay que anadir los recogidos por P. Marchetti y por P. Visonà en Sicilia y el sur de Italia ${ }^{+11}$. De Cerdeña se recogen pocos hallazgos de este tipo de monedas: 3 en el Museo de Cagliari, 8 en la colección Forteleoni, una en la colección Biggio y otra de Tharros. Sin embargo se reseña un número mayor en Malta junto a los dos hallazgos citados de Pantelleria ${ }^{+1}$. Por su parte B. Fischer recoge los hallazgos de monedas africanas en Gallia, documentando monedas similares a las de nuestro tesorillo en Creil (3 SNGCop 324), Lattes (1 SNGCop 319), Mareuil-Sur-Arnon (1 SNGCop 307), Ozouer-Le-Vougis (1 SNGCop 320) y Penmarch'h (1 SNGCop 320) +2.

Por último, en la peninsula ibérica, islas adyacentes y parte más occidental del Norte de África (fig. 5), hemos localizado hallazgos de monedas de estos tipos en:

1.- I del tipo II en el hallazgo de 1749 de Corvo en las islas Azores ${ }^{43}$.

2. - I del tipo I en Garciaz (Cáceres), hallada en un estrato tardo-romano junto a 1634 pequeños bronces romanos de los siglos III y IV d.C. ${ }^{+4}$.

3.- Torre de Doña Blanca (Cádiz). Además del tesoro de 56 monedas que comentamos, también se halló fuera de contexto arqueológico otra moneda del tipo $\mathrm{II}^{45}$.

\footnotetext{
${ }^{3 x}$ Bateson, D., Campbell, I. y Visona, P.: The Early Nienteenth-Century Jackson Collection of Coins from Carthage, The Numismatic Chronicle, 1990, pp. 155-156, $\mathrm{n}^{\circ} 25-48$. Mas de la mitad de las monedas púnicas de esta colección pertenecen al periodo de la Segunda Guerra Púnica.

${ }^{39}$ Buttrey, T, V., Erim, K. T., Groves, T. D. y Ross Hollway, R.: Morgantina Studies. II. The Coins, New Jersey, 1989, $\mathrm{n}^{\circ} 443$. Este número incluye las 6 monedas halladas que cataloga P. Visonà

40 Marchetti, P.: Histoire économique et monétaire de la deuxième guerre punique, Bruselas, 1978, pp. 489-490 y Visona, P.: Carthaginian Bronze Coinage in Southern Italy and Sicily during the Second Punic War, Proceedings of the 10th International Congress of Numismatics, Londres, 1986, p. 87, nota 19

41 Jenkins, 1987, pp. 216-217.

${ }^{42}$ Fischer, B.: Les monnaies antiques d'Africa du nord trouvées en Gaule, Supplement a Gallia, XXXVI, 1978, $\mathrm{n}^{\circ} 11,18,21,32$ y 33 .

${ }^{43}$ Monod, T.: Les monnaies nord-africaines anciennes de Corvo (Açores), Bulletin de I'I.F.A.N., XXXV, B, 2, 1973, lám. 6, $\mathrm{n}^{\circ} 6$

${ }^{44}$ Callejo Serrano, C.: Los bronces romanos de Garciaz, Revista de Estudios Extremeños, XXII-XXIII, 1966, pp. 299-300, lám. 1, a.

45 Alfaro y Marcos, TDB.
}

4. I del tipo II en el poblado de Las Cumbres en la Sierra de San Cristobal (Puerto de Santa Maria. (ädiz) ${ }^{\text {th }}$.

5. -5 de distintos tipos en (adiz ${ }^{4}$.

6. - 2 en Carteia (Cádiz) de los tipos II con 'aleph y IV con num o lamed, según las láminas de la antigua colección Carter del siglo xvIII $^{+x}$.

7.-Monedas de los tipos l y II en distintos campamentos militares cartagineses de Andalucia Oriental: La Tablada, Alhonoz, Cerro Perea, La Camorra, Pedro Abad, La Nava, Ubeda, Cazorla, Puente del Obispo, Cerro de la Mora y Cerro Colomera que fundamentalmente se situan en la margen izquierda del Guadalquivir ${ }^{40}$.

8.-Gran hallazgo de miles de monedas cartaginesas, pensamos que de estos tipos, en la provinca de Jaén, al parecer dentro de una caja metálica. Puede ser una caja para pagos del ejército de ocupación en Hispania, lo que pondría de manifiesto la importancia de estas monedas para la financiación de la guerra y habría que añadir su potencial a las cifras que maneja Villaronga para los bandos contendientes ${ }^{50}$.

9.-1 del tipo II en Cerro del Mar (Velez Málaga) ${ }^{51}$

10. -3 en Alicante 52 .

11.-1 de probable hallazgo local se conserva en el Museo de Albacete.

12. - I del tipo II hallada en Cruce de 4 caminos (Macastre-Alborache, Valencia) ${ }^{53}$.

13. - 3 del tipo II en la colección de la Universi-

th Alfaro $y$ Marcos. TDB.

4) Tres en el Museo de Cádiz, números 2940, 2939 y 16759 que, como el resto del numerario del museo, proceden de la provincia. Otra pieza recogida por Vidal González, P.: Los hallazgos monetales del catálogo de J. Gaillard, Saguntum. 22, 1989. $\mathrm{n}^{\circ} 40$. El último ejemplar procedente de la caja de seguridad del Banco Español de Crédito, depositada en el Gabinet Numismàtic de Catalunya.

4x Rodriguez Oliva, P.: Noticias numismáticas de la Andalucia mediterránea (1), Numisma, XXXIII, 180-185, 1983, p. 121 , lám. $1, \mathrm{n}^{\circ} 3$ y 1 respectivamente.

${ }^{49}$ Chaves Tristan, F.: Los hallazgos numismáticos y el desarrollo de la Segunda Guerra Púnica en el sur de la peninsula ibérica, Latomus, 3, 1990, pp. 613-622.

50. Agradecemos la información al Dr. Ivan Negueruela.

5t Rodriguez Oliva, P.: Noticias numismáticas de la Andalucia mediterránea (I), citado, p. 124, lám. II.

${ }_{22}$ Ripollés, P. P.: La circulación monetaria en la Tarraconense mediterránea, Valencia, 1983, p. 215-216, $\mathrm{n}^{\circ} 10$ y 11 , conservadas en el Museo Arqueológico de Alicante. (En adelante citado como Ripollés, 1983.) Son del tipo SNGCop 309 ó 317 . La moneda $\mathrm{n}^{\circ}$ 55 de $6,70 \mathrm{~g}$., clasificada en dicha publicación como hispanocartaginesa de la serie $\mathrm{X}$ de Villaronga, 1973, pensamos se corresponde con nuestro grupo V, del tipo SNGCop 326-329.

53. Arroyo llera, R: Mata Parreño, C., y Ribera i Lacomba, A.: Aproximación a la circulación monetaria de las comarcas interiores de la provincia de Valencia, Saguntum, 22, 1989, $n^{\circ} 71$, la describen como hispano-cartaginesa con prótomo de caballo. 
dad de Valencia de probable hallazgo local ${ }^{54}$. A esta cifra podemos añadir otros 3 ejemplares de la antigua colección valenciana de D. Pablo Bosch, conservada actualmente en el Museo del Prado.

14. - 3 del tipo II en el Cerro de San Miguel de Lliria (Valencia) ${ }^{55}$.

15.-1 del tipo IV en el Grau Vell (Sagunto. Valencia) ${ }^{56}$.

16. - 11 de casi todos los tipos en Ampurias (Gerona) halladas en las distintas campañas de excavación llevadas a cabo en el yacimiento. A esta cifra se pueden añadir otras 7 monedas conservadas en los fondos del Gabinet Numismàtic de Catalunya que con probabilidad también fueron halladas en la zona $^{57}$.

17. - 1 del tipo $\mathrm{V}$ en Mahón (Menorca) ${ }^{58}$.

18. - 3 monedas, al menos, en Ibiza, una del tipo $\mathrm{I}$, otra del tipo $\mathrm{II}^{54}$ y la tercera del tipo $\mathrm{V}$ hallada en San Antonio ${ }^{60}$.

19.--Millares en el dragado del puerto de MeliIIa, posiblemente transportadas en un barco cartaginés hundido ${ }^{61}$.

La cronologia de las monedas del tesorillo es muy precisa, 221-210 a.C., por varios motivos. En primer lugar por las reacuñaciones de monedas de nuestros grupos segundo y tercero que se han constatado sobre monedas de finales del reinado de Hierón II de Siracusa que murió en el 215 a.C. ${ }^{62}$. También monedas de nuestro grupo quinto reacuñan sobre uncias romanas del 214-212 a.C. ${ }^{63}$. Del mismo modo estas monedas cartaginesas fueron utilizadas como cospel por los romanos para acuñar sus semiuncias del 217-215 y uncias del 214-212 a.C. ${ }^{64}$. Igualmente este tipo de monedas son frecuentes en contextos de la Segunda Guerra Púnica y en ocasiones se hallan en estratos arqueológicos datables en estas fe-

pero la fotografia que ilustra la moneda en la lám. III no se corresponde con esta descripción y si con una pieza de Cartago del tipo II.

${ }^{44}$ Arroyo llera, R.: Numario de la Universidad de Valencia, Valencia, 1984, nn. 571-573.

55 Villaronga, 1973, p. 173.

so Ripollés, 1983, p. 98.

57 Alfaro Asins, C.: Monedas cartaginesas y norteafricanas halladas en Ampurias, Huelva Arqueógica, (en prensa).

$3 \pi$ Ripollés, 1983, p. 235, $\mathrm{n}^{\circ} 4$. Creemos puede corresponder al tipo SNGCop 326-329.

59 Museo de lbiza, números 11976 y 11079 . Ripollẻs, 1983. p. $244, n^{\circ} 16$ y 17 , la primera mal clasificada.

* Museo de Ibiza, n 12819.

bi Alfaro, Melilla.

B2 Jenkins y Lewis, p. 136, pl. 28-9. SNGCop 323 y 325. Jenkins, 1987 , B 10 y 12.

os Crawford, M. H.: The Roman Republican Coinage, Cambridge, 1974, n42/4. Jenkins, 1987, p. 217, lám. F, Bbx.

H Crawford, M. H.: The Roman Republican Coinage, citado, $n^{\circ} 38 / 7$ y $n^{\circ} 42 / 4$ respectivamente. chas, como sucede en Morgantina (Sicilia), donde un ejemplar apareció al excavar la llamada "casa del hallazgo de plata" en el estrato correspondiente a la captura de la ciudad en el 211 a.C. ${ }^{\circ 5}$.

Este tesorillo que comentamos es uno de los materiales arqueológicos más importantes recuperados en el yacimiento ya que, gracias a la clara cronologia de las monedas que lo forman y en estrecha relación con el nivel de incendio y destrucción donde se hallaron, nos proporciona con exactitud la fecha final de la vida del yacimiento, inicialmente fijada a finales del siglo Iv a.C., y que gracias al testimonio numismático podemos situar en los prolegómenos del 206 a.C., momento de la expulsión de los cartagineses de la Peninsula tras su derrota en llipa.

Las monedas del tesorillo hallado en este yacimiento están en estrecha relación con las recuperadas en el dragado del puerto de Melilla que probablemente pertenecen a la carga de un barco hundido procedente de Cartago a finales del siglo II a.C. Las monedas recuperadas pertenecen en su mayor parte a la Segunda Guerra Púnica, con una presencia testimonial de monedas sículas del siglo Iv a.C., sardas de la primera mitad del III a.C. y cartaginesas anteriores al citado conflicto bélico. Estas monedas, por el gran número en que fueron recuperadas, parece que pudieron estar destinadas al pago de tropas y no permite asociarlas a dinero de bolsillo de sus tripulantes.

El puerto de Rusadir tuvo una gran importancia en la antigüedad como escala de navegación y de avituallamiento en las rutas maritimas en dirección a las Columnas de Hércules a lo largo de la costa norteafricana y hacia la península ibérica y viceversa. Este puerto era escala indispensable en la navegación de cabotaje seguida por los cartagineses en el Norte de África, como nos documenta el Periplo de Scylax en el siglo iv a.C., y precedía a la gran masa rocosa del cabo de Tres Forcas, denominada Metagonium por los griegos y Rusadir por los fenicio-púnicos, desde donde los barcos procedentes de Cartago enfilaban con facilidad hacia la costa del cabo de Gata y Cartagonova. En dirección contraria, la navegación desde Malaca y Seks tenía condiciones muy positivas en cuanto a corrientes y vientos para llegar a la costa africana de las proximidades de Rusadir ${ }^{66}$.

Esta facilidad de comunicación naval entre Ibe-

\footnotetext{
${ }^{63}$ Buttrey, T. V.; Erim, K. T.; Groves, T. D., y Ross Holloway, R.: Morgantina Studies, II. The Coins, citado, p. 162.

wh Sobre las rutas de navegación entre Rusadir y Cartago y Rusadir y la Peninsula ver Gozalbes, E.: Economia de la ciudad antigua de Rusadir, Aldaba, 9, 1987, pp. 101-111. Gozalbes, E.:
} 
ria y el Norte de África, fundamentalmente la zona de la Metagonia. propicio los constantes transvases de soldados que se efecturaron desde el 237 a.C. y durante toda la Segunda (iuerra Púnica, como sabemos por las fuentes. Asi, por ejemplo, en el 216 a.C. se envian a Asdrúbal desde Africa 4.000 infantes y 1.000 jinetes (Livio, XXIII, 26). En el 215 a.C. nuevamente se envian refuerzos al mando de Magón a la Peninsula (Livio, XXIII, 32). En el 211 las fuentes citan tropas cartaginesas invernando en Turdetania y en el 208 caballeria numida y africana a las órdenes de Asdrúbal (Livio, XXVII, 18). En el 207 a.C. nuevamente se cita un ejército cartaginés que pasa a la Peninsula (Livio, XXVIII, 1). En el 206 se cita a Masinissa, como dos años antes, al frente de los númidas en Iberia. Incluso después de la expulsión de los cartagineses de la Peninsula en 206 a.C., las fuentes nos hablan de tropas reclutadas por Magón en el Norte de África para pasar a lberia y viceversa (Livio, XXIII, 29) ${ }^{\circ 7}$. Es especialmente importante el dato transmitido por Polibio (III, 33, 8-13) referente al gran contingente de tropas peninsulares que Aníbal acantonó en la región de Metagonium, al principio de la guerra, para proteger tanto la retaguardia como esta conexión maritima, evaluada en 3.000 estadios, entre Rusadir y Cartagonova.

Evidentemente parece tentador pensar que el numerario de la nave cartaginesa hundida en el puerto de Rusadir que comentamos, podía estar destinado para pagar a los mercenarios acantonados en esta zona de la actual Melilla, o en sucesivas escalas de navegación del Norte de África en dirección al estrecho de Gibraltar, durante los años del conflicto bélico.

Aunque sabemos que los mercenarios exigian su soldada en oro y plata, estas monedas de "cobre» de bajo poder adquisitivo, podrian servirles para los gastos de su mantenimiento en las ciudades $y$, desde el punto de vista cartaginés, sobre todo para evi-

La ciudal antigua de Rusadir. Aportaciones a la historia de Melilla en la antigüedad, Melilla, 1991, pp. 29-54, (En adelante citado como Gozalbes, 1991.) Alvar, J.: La precolonización y el tráfico maritimo fenicio por el Estrecho, Actas I Congreso Internacional El Estrecho de Gibraltar, Madrid, 1988, pp. 429. 443. Fernández Miranda, M.: La navegación fenicia hacia el lejano Occidente y el Estrecho de Gibraltar, Actas I Congreso Internacional El Estrecho de Gihrultur, Madrid, 1988, pp. 459-472. Gran Aymerich, J. J.: Málaga fenicio-púnica y el Estrecho de Gibraltar, Actas I Congreso Internacional El Estrecho de Gibraltar, Madrid, 1988, pp. 577-591.

67 Estos y otros muchos datos recogidos por Blázquez, J. M.: Las relaciones entre Hispania y el Norte de África durante el gobierno Bárquida y la conquista romana (237-19 a. J.C.), Saitabi, X1, 1961, pp. 21-43. (En adelante citado como Blázquez. 1961.) tar la desercion inmediata de las tropas por la carencia de monedas fuertes con que realizar el pago a las mismas. como muy bien ha visto Gozalbes ${ }^{\text {ix }}$. Basta recordar la grave revuelta de los mercenarios motivada por la falta de cobro de la soldada al final de la Primera Guerra Púnica que. a veces, se ha puesto en relación con la pérdida de las minas hispanas antes del 240 a.C. como algunos autores deducen del texto de Polibio (1. 10, 5$)^{\circ \%}$.

Muchas de estas monedas "de necesidad", acuñadas precipitadamente en Cartago, pasaron con los mercenarios también a la peninsula ibérica, como prueban los abundantes hallazgos y, en especial, el tesorillo de la Torre de Doña Blanca, que debe ser la bolsa de un soldado recién llegado a la Península desde el Norte de África en los últimos años del conflicto bélico en estas tierras. Esta bolsa o tesorillo se formó con numerario de distintos tipos circulante en esos momentos en el área de Cartago, como lo indica la ausencia de monedas acuñadas en otras zonas como por ejemplo Sicilia. El numerario se debió atesorar paulatinamente aunque en un espacio muy corto de tiempo, $\mathrm{e}$ incluso pudo ser producto de un pago estatal a pesar de que las monedas presentan distinto grado de desgaste. La bolsa debió llegar al yacimiento traída por un soldado recien venido del Norte de África pues éste no tuvo tiempo de incluir en élla monedas de valor similar acuñadas por los cartagineses en Hispania.

Sabemos además que estas monedas subsidiarias de "cobre-plomo" se enviaron a Italia y Sicilia desde Cartago durante la guerra de Aníbal. Los hallazgos de este tipo de piezas en Sicilia son muy abundantes y parecen asociarse con claridad a la expedición del 213-210 a.C. que fue duramente financiada por Cartago, a la vista del escaso numerario de bronce emitido por Anibal en Italia ${ }^{70}$.

Cabe también la posibilidad de que, en algún momento de graves dificultades económicas del bando cartaginés, este numerario de socorro acuñado en Cartago hubiera podido servir igualmente para el pago de tropas mercenarias en Iberia, como quizás pueda deducirse de algún gran hallazgo de este tipo de monedas como el de la provincia de Jaén.

Estos momentos dificiles podrian muy bien localizarse inmediatamente antes de la expulsión de los cartagineses de la península ibérica (c. 209-206 a.C.), cuando ya no se podian acuñar monedas en Iberia, fundamentalmente, por la pérdida de las minas de la zona de Cartagonova. En este sentido,

\footnotetext{
hK Gozalbes, 1991, p. 53.

69 Blázquez, 1961, p. 24.

7 Visonà, 1986, pp. 86-87.
} 
(rawford opina que los cartagineses dejaron de acunar en Hispania después de la pérdida de Cartagonova en 209 y antes de marchar Asdrubal a Italia en 207. desapareciendo rapidamente su numerario de la circulación ". Los bárquidas explotaron intensivamente las minas de plata de Cartagena y, como se piensa desde el siglo pasado. la rápida conquista de esta ciudad por Escipión en 209 a.C. obedeció más a la necesidad de controlar sus ricas minas, que financiaron parte de la Segunda Guerra Púnica, que a privar a los cartagineses del mejor puerto levantino para contactar con África e Italia ${ }^{72}$.

\section{CATÁLOGO $^{73}$}

\section{TIPOI}

Anv.-Cabeza de Tanit a izquierda. Gráfila lineal ( $\left.n^{\circ} 3\right)$.

Rev.-Caballo al paso a derecha con ronzal y la cabeza vuelta. Entre las patas puede llevar letras púnicas. Gráfila lineal $\left(\mathrm{n}^{0} 1 \text { y } 3\right)^{74}$.

1. Sin letras

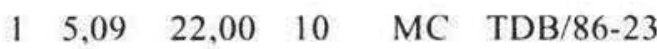

2. Letra aleph

$$
2 \quad 5,86 \quad 20-21 \quad 12 \quad \text { RC } \quad \text { TDB } / 86-40
$$

3. Letra gimel

$\begin{array}{rlrl}3 \quad 7,13 \quad 20-22 \quad 12 \quad \text { RC } & \text { TDB/86-31. } \\ & \text { Glóbulo en } \\ & \text { anv. delante } \\ & & \text { del cuello. }\end{array}$

\section{TIPO II}

Anv.-Cabeza de Tanit a izquierda. Gráfila de puntos (nn. 5, 16, 24, 25) o lineal (nn. 11, 19, 20).

\footnotetext{
$"$ Crawford, M. H.: Coinage and Money under the Roman Republic, 1985, p. 87.

72 Blázquez, 1961, p. 24.

73 A continuación del número de órden de cada moneda figuran el peso en gramos, el módulo en milimetros, la posición de cuños expresada en horas, la conservación, el $\mathrm{n}^{\circ}$ de inventario y ocasionalmente observaciones. Los corchetes que unen numeros de orden indican identidad de cuño de anverso ([) o reverso (]) entre dos o más monedas.

${ }^{74}$ SNGCop 302-306. Acquaro, E.: La monetazione punica. Catalogo delle Civiche Raccolte Numismatiche di Milano, Milán, 1979, 29-31. (En adelante citado como Acquaro, 1979.) Jenkins, $1987, B 2,3$ y 4
}

Rev. Caballo parado a derecha con ronzal y la cabeza vuelta. En el campo a la derecha y entre las patas puede llevar letras púnicas. Gráfila de puntos ( $\mathrm{nn} .5$ ) o lineal $(\mathrm{nn}$. $4,6,7,10,11,14,16,18,21,24,25,26)^{7}$.

\begin{tabular}{|c|c|c|c|c|}
\hline $4 \quad 7,46$ & 21,00 & 11 & MMC & TDB/86-46 \\
\hline 6.74 & $21-22$ & 12 & $\mathrm{RC}$ & TDB/86-54 \\
\hline 6,69 & $22-23$ & 12 & $M C$ & TDB/86-19 \\
\hline 6.43 & 23.00 & 12 & $\mathrm{MC}$ & $\mathrm{TDB} / 86-17$ \\
\hline 6,08 & $20-22$ & 12 & $\mathrm{MC}$ & TDB/86-28 \\
\hline 5,81 & $20-21$ & 12 & $\mathrm{MC}$ & ТDB/86-56 \\
\hline 5,68 & 20,00 & 12 & $\mathrm{MC}$ & TDB/86-11 \\
\hline 5,36 & $22-24$ & 12 & $\mathrm{RC}$ & TDB/86-2 \\
\hline 5,20 & $19-22$ & 12 & $\mathrm{BC}$ & $\mathrm{TDB} / 86-25$ \\
\hline 5,10 & $19-21$ & 12 & $\mathrm{RC}$ & $\begin{array}{l}\text { TDB/86-52. } \\
\text { Fragmentada y } \\
\text { reconstruida }\end{array}$ \\
\hline 4,85 & 20,00 & 12 & $\mathrm{RC}$ & TDB/86-43 \\
\hline 4.56 & $20-21$ & 12 & $\mathrm{RC}$ & $\begin{array}{l}\text { TDB/86-34. } \\
\text { Reacuñada }\end{array}$ \\
\hline
\end{tabular}

1. Sin letras

2. A la derecha 'aleph

$\begin{array}{llllll}16 & 6,06 & 21,00 & 12 & \mathrm{RC} & \mathrm{TDB} / 86-16 \\ 17 & 5,61 & 20-21 & 12 & \mathrm{RC} & \mathrm{TDB} / 86-41 \\ 18 & 4,86 & 21,00 & 12 & \mathrm{MC} & \mathrm{TDB} / 86-20\end{array}$

3. A la derecha 'aleph y entre las patas sade

$\begin{array}{llllll}19 & 6,92 & 21,00 & 12 & \mathrm{BC} & \mathrm{TDB} / 86-38 \\ 20 & 6,51 & 19-22 & 12 & \mathrm{BC} & \mathrm{TDB} / 86-30 \\ 21 & 5,64 & 21-23 & 12 & \mathrm{RC} & \mathrm{TDB} / 86-44 \\ 22 & 5,21 & 19-22 & 2 & \mathrm{MC} & \begin{array}{l}\text { TDB/86-26. } \\ \text { Fragmentada }\end{array} \\ 23 & 4,90 & 20-21 & 12 & \mathrm{MC} & \begin{array}{l}\text { TDB/86-49. } \\ \text { Fragmentada }\end{array}\end{array}$

4. A la derecha het

$\left.\begin{array}{l}24 \\ 25\end{array}\right] \begin{array}{lllll}8,62 & 21,00 & 12 & \mathrm{RC} & \mathrm{TDB} / 86-9 \\ 7,03 & 22-24 & 12 & \mathrm{BC} & \begin{array}{l}\text { TDB/86-4. } \\ \text { Cuño de anv. } \\ \text { descentrado }\end{array}\end{array}$

5. Entre las patas ¿mem?

\section{$26 \quad 4,94 \quad 20-21 \quad 12 \quad$ RC $\quad$ TDB/86-13}

75 SNGCop 307-314. Acquaro, 1979, 32-35. Jenkins, 1987. B6-B10. 
6. Entre las patas sade

$$
27 \quad 4,85 \quad 20,00 \quad 12 \quad \text { RC TDB/86-18 }
$$

\section{TIPO III}

Anv.-Cabeza de Tanit a izquierda.

Rev.-Caballo parado a derecha con ronzal y la cabeza vuelta. Encima estrella de 7 puntas. Entre las letra púnica ¿het? Gráfila lineal ${ }^{7 n}$.

$28 \quad 7,17 \quad 20-22 \quad 12 \quad$ RC TDB/86-33

\section{TIPO IV}

Anv.-Cabeza de Tanit a izquierda. Gráfila de puntos (nn. 40, 43) o lineal (nn. 35).

Rev.-Caballo parado a derecha con ronzal y la cabeza vuelta, detrás palmeta. A la derecha puede llevar letras púnicas. Gráfila lineal (nn. 29, 34, 35, 43) ${ }^{7 ?}$.

1. Sin letras

$$
\begin{array}{rrrrrrl}
29 & 9,02 & 22-24 & 12 & \mathrm{BC} & \begin{array}{l}
\text { TDB/86-6. } \\
\text { Quizás letra } \\
\text { ikaph? }
\end{array} \\
30 & 8,96 & 21-23 & 12 & \mathrm{RC} & \mathrm{TDB} / 86-7 \\
31 & 8,75 & 22-23 & 12 & \mathrm{RC} & \mathrm{TDB} / 86-8 \\
{\left[_{32}\right.} & 8,38 & 20-23 & 12 & \mathrm{RC} & \mathrm{TDB} / 86-10 \\
33 & 8,22 & 21-22 & 12 & \mathrm{RC} & \mathrm{TDB} / 86-5 \\
34 & 7,51 & 21-22 & 12 & \mathrm{MC} & \mathrm{TDB} / 86-48 \\
35 & 7,10 & 21-23 & 12 & \mathrm{RC} & \mathrm{TDB} / 86-12 \\
36 & 6,32 & 19-22 & 12 & \mathrm{MC} & \mathrm{TDB} / 86-55 \\
37 & 5,57 & 22,00 & 12 & \mathrm{MC} & \mathrm{TDB} / 86-29 \\
38 & 5,25 & 22-23 & 12 & \mathrm{MC} & \begin{array}{l}
\text { TDB/86-51. } \\
\text { Tragmentada y }
\end{array} \\
& & & & & \begin{array}{l}
\text { Fragmstruida } \\
\text { recons }
\end{array}
\end{array}
$$

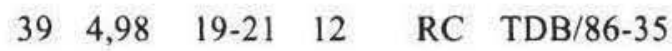

2. Letra gimel

$$
\begin{array}{rrrrrl}
40 & 7,96 & 23-29 & 12 & \mathrm{RC} & \mathrm{TDB} / 86-42 \\
41 & 7,96 & 21-22 & 12 & \mathrm{MC} & \begin{array}{l}
\text { TDB/86-50. } \\
\text { Fragmentada y } \\
\text { reconstruida }
\end{array}
\end{array}
$$

\section{$\begin{array}{llllll}42 & 7,15 & 21-22 & 12 & R C & T D B\end{array} / 86-27$ \\ $43 \quad 4,12 \quad 21-22 \quad 12 \quad \mathrm{RC} \quad \mathrm{TDB} / 86-15$}

3. Letra nun o lamed

$$
\begin{array}{llllll}
44 & 7.58 & 21-22 & 12 & \mathrm{MC} & \mathrm{TDB} / 86-45
\end{array}
$$

\section{TIPO V}

Anv.-Cabeza de Tanit a izquierda. Gráfila de puntos (nn. 45, 47-51) o lineal (nn. 46, 53-55).

Rev.-Caballo al paso a derecha y detrás caduceo. Entre las patas puede llevar letras púnicas. Gráfila de puntos (nn. 45, 47-51, $53-55)$ o lineal $\left(n^{\circ} 46\right)^{78}$.

1. Sin letras

$$
\left[\begin{array}{rrrrrrl}
45 & 8,28 & 22-23 & 12 & \mathrm{MC} & \begin{array}{l}
\text { TDB/86-14 } \\
\text { ¿Reacuñada? }
\end{array} \\
46 & 7,98 & 22-23 & 12 & \mathrm{RC} & \text { TDB/86-37 } \\
47 & 7,96 & 22,00 & 12 & \mathrm{RC} & \mathrm{TDB} / 86-24 \\
48 & 7,35 & 21,00 & 12 & \mathrm{RC} & \mathrm{TDB} / 86-21 \\
49 & 6,97 & 21-22 & 12 & \mathrm{RC} & \mathrm{TDB} / 86-1 \\
50 & 6,40 & 21,00 & 12 & \mathrm{RC} & \mathrm{TDB} / 86-32 \\
51 & 5,96 & 21-22 & 12 & \mathrm{RC} & \mathrm{TDB} / 86-36 \\
52 & 5,85 & 17-22 & 12 & \mathrm{MC} & \mathrm{TDB} / 86-47 . \\
& & & & & \text { Fragmentada }
\end{array}\right.
$$

2. Letra ayin

$$
\begin{aligned}
& 53 \quad 8,59 \quad 21-22 \quad 12 \quad \text { BC } \quad \text { TDB } / 86-3 \\
& {\left[\begin{array}{llllll}
54 & 7,70 & 21-23 & 12 & \mathrm{MC} & \mathrm{TDB} / 86-53
\end{array}\right.} \\
& \begin{array}{llllll}
55 & 6,82 & 21,00 & 12 & \text { RC } & \text { TDB/86-22. }
\end{array} \\
& \text { Reacuñada }
\end{aligned}
$$

\section{TIPO VI}

Anv.-Cabeza de Tanit a izquierda. Gráfila lineal.

Rev.-Caballo parado a derecha con ronzal. Encima una estrella de 8 puntas. A la derecha letra púnica ayin. Gráfila lineal ${ }^{79}$

$\begin{array}{llllll}56 & 9,44 & 22-23 & 12 & \text { BC } & \text { TDB/86-39 }\end{array}$

\footnotetext{
76 SNGCop 315-316. Jenkins, 1987, B 11 B 12

77 SNGCop 317-319.
}

\footnotetext{
7* SNGCop 326-329.

70 Alfaro, Melilla y Ampurias.
} 

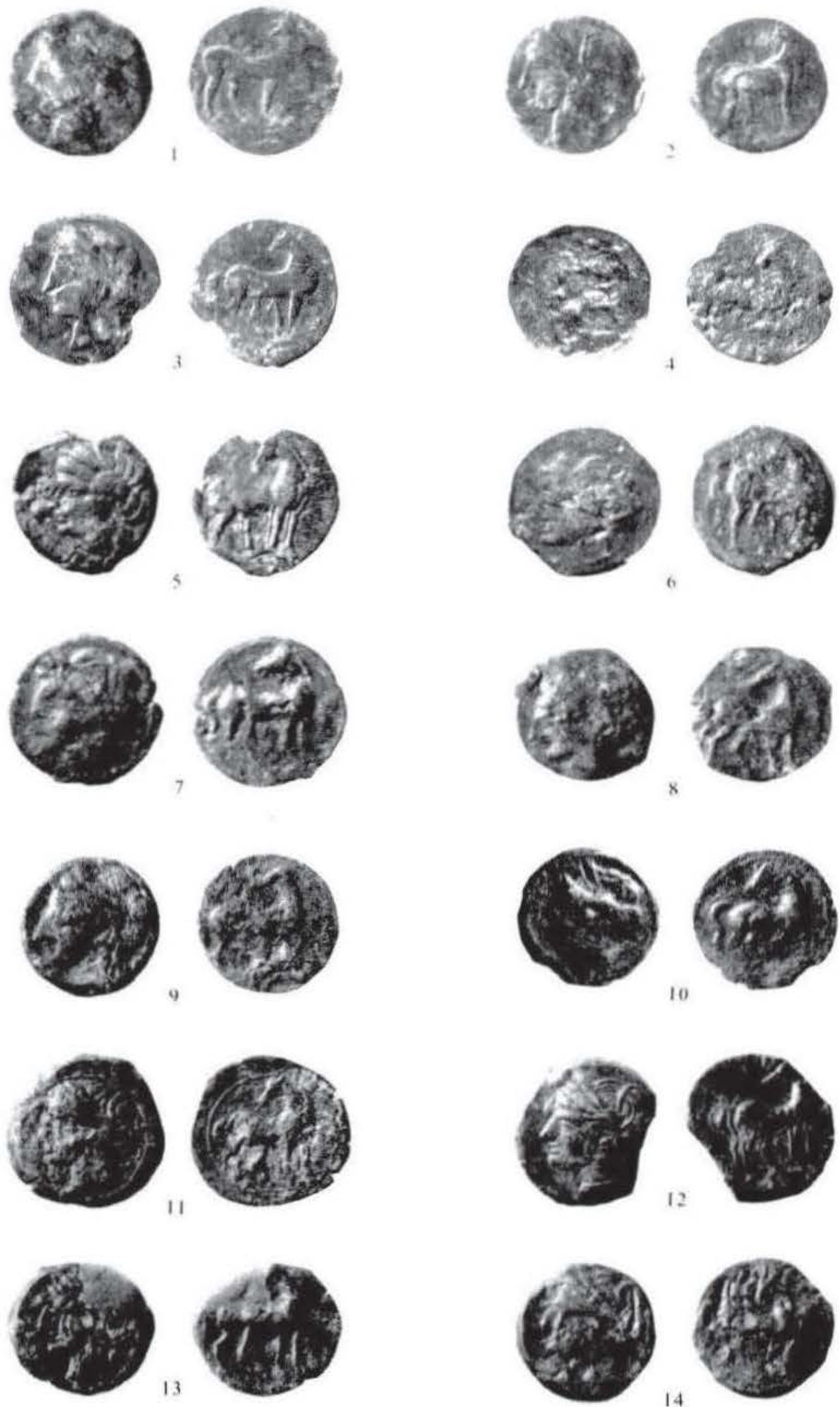

Figura 6. - Las monedas del Tesorillo de la Torre de Doǹa Blanca (Cadiz). 

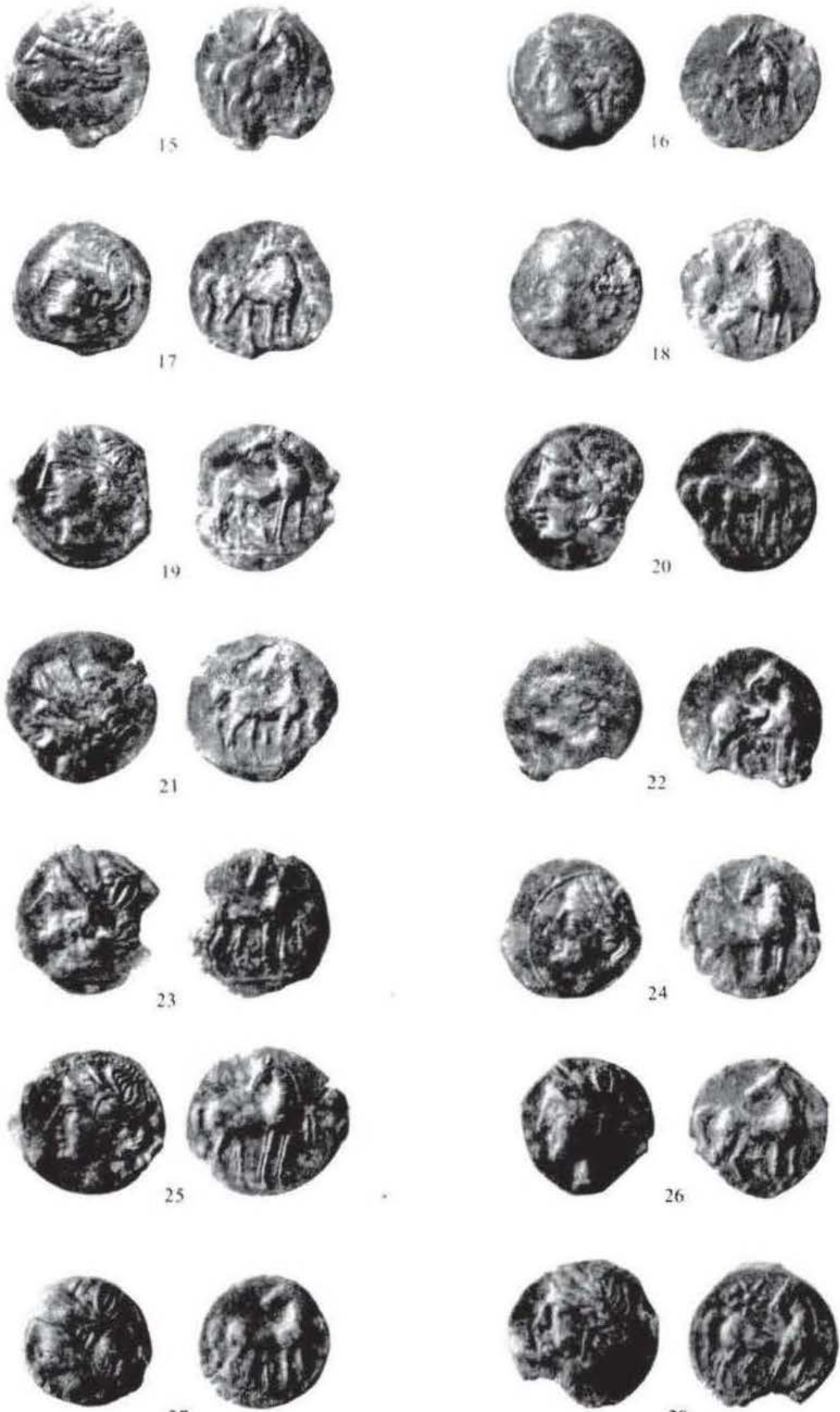

27

28

Figura 7.- Las monedas del Tesorillo de la Torre de Dona Blanca (Cádiz). 

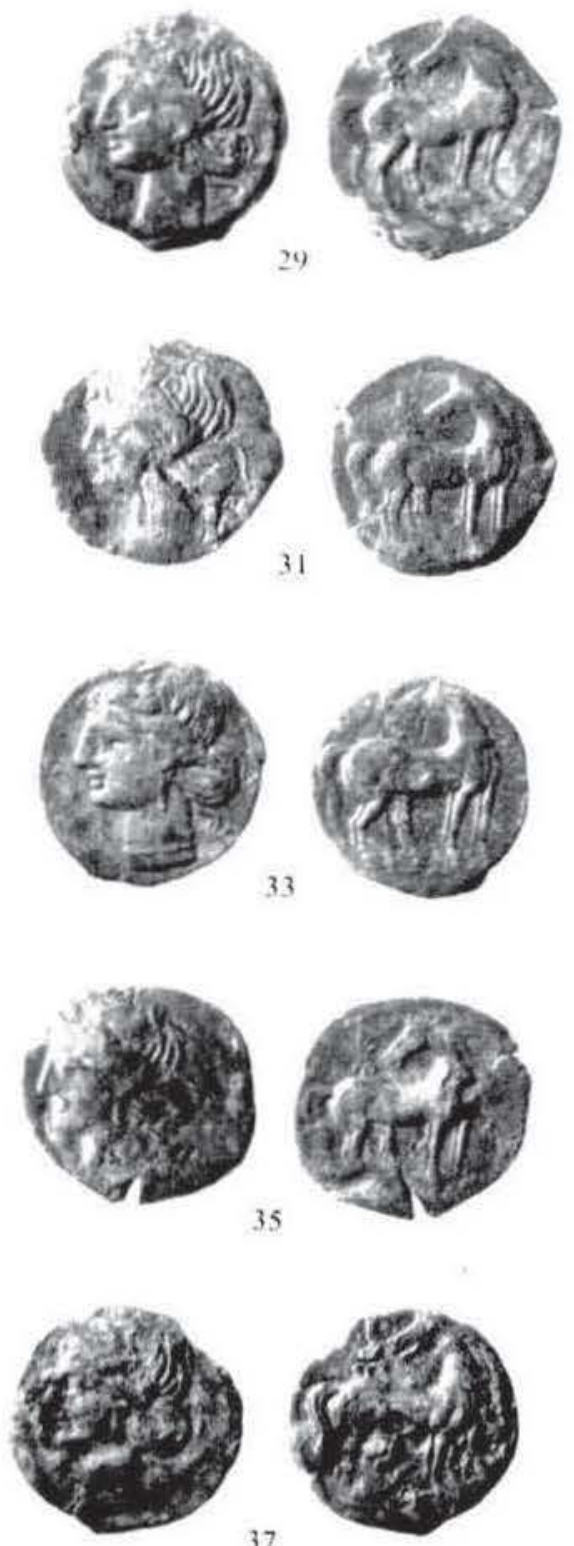

37
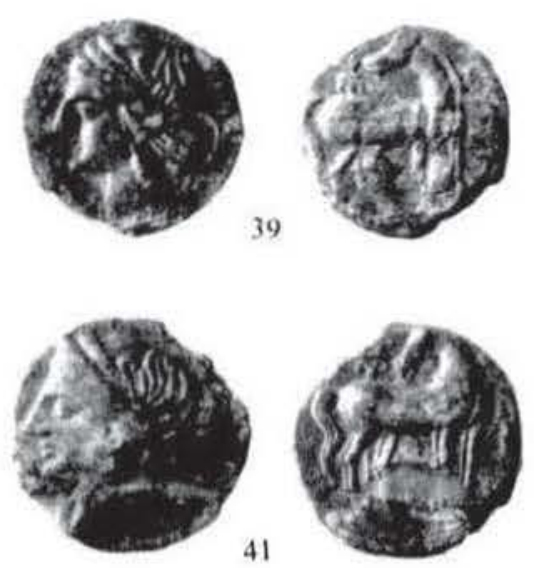
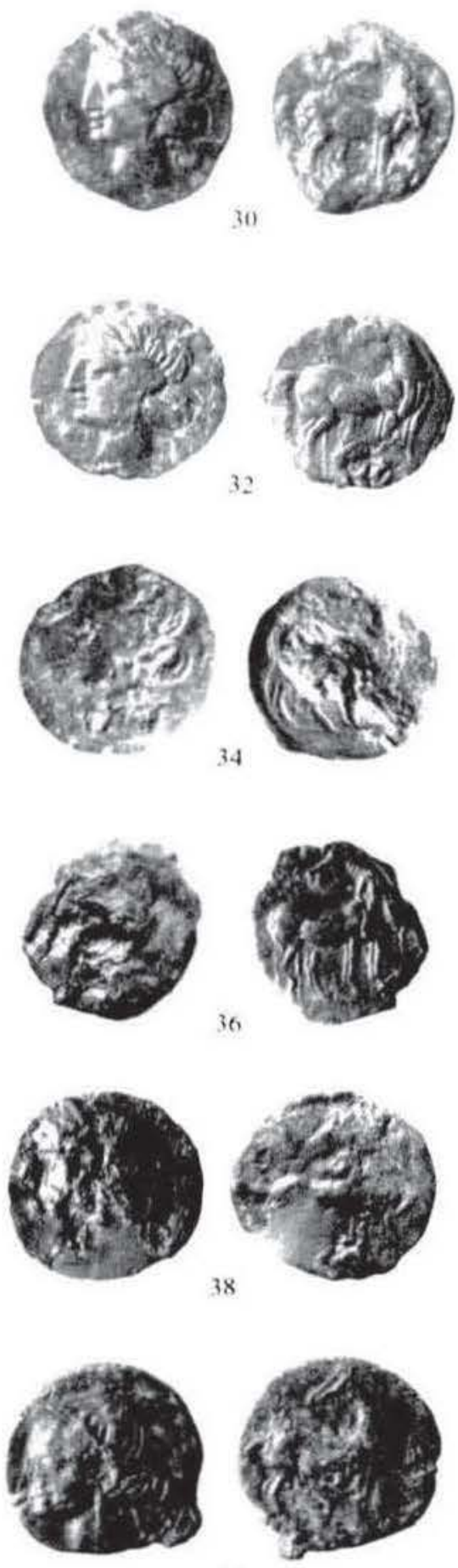

40

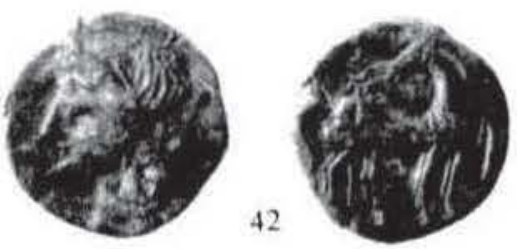

Figura 8.-Las monedas del Tesorillo de la Torre de Dona Blanca (Cádiz). 

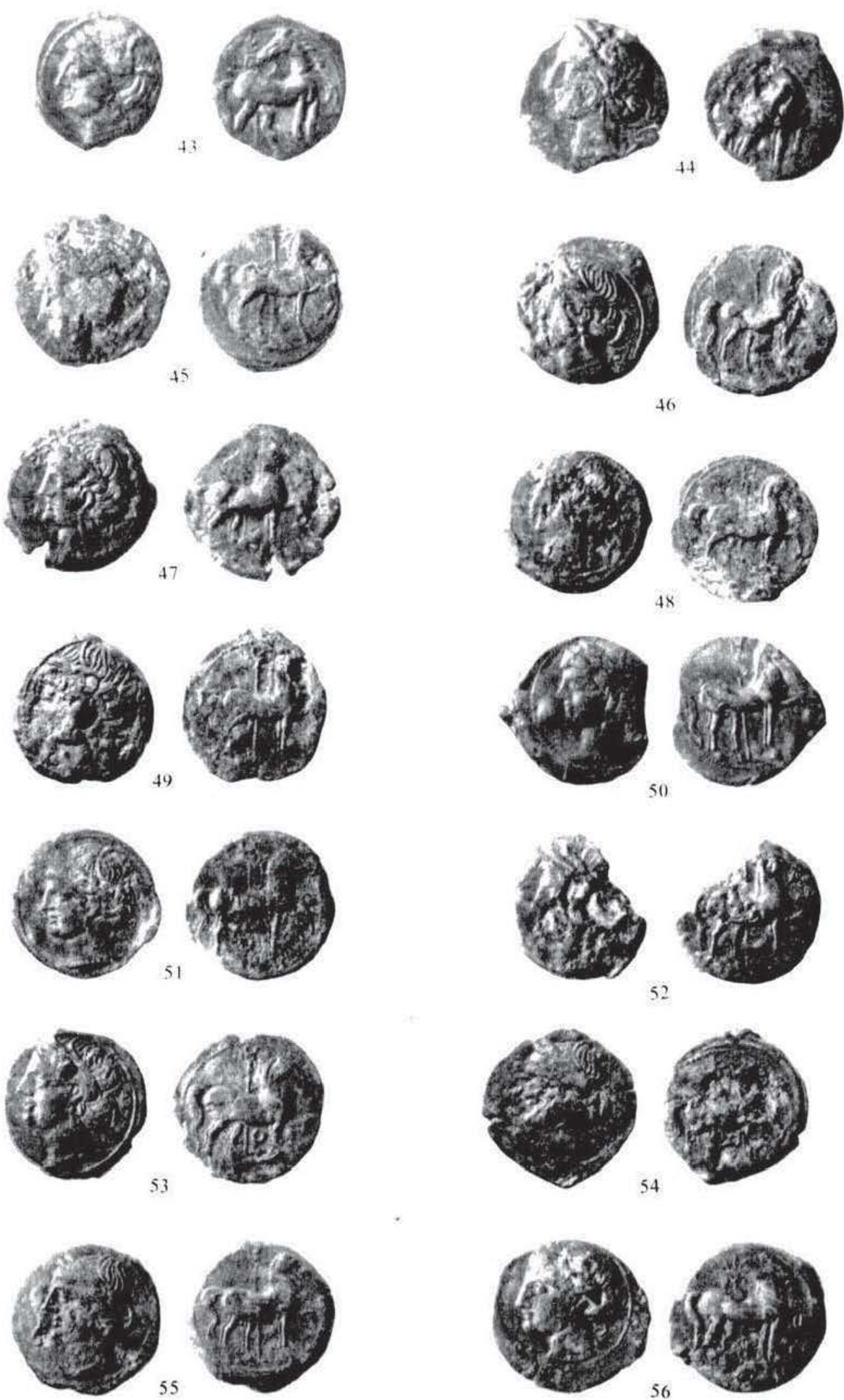

Figura 9,- - Las monedas del Tesorillo de la Torre de Dona Blanca (Cádiz). 